\title{
КИНЕТИКА ФОТОХИМИЧЕСКОГО ПРЕВРАЩЕНИЯ 3,4-БЕНЗПИРЕНА В АЭРИРОВАННОМ БЕНЗОЛЬНОМ РАСТВОРЕ
}

Тяжелая часть смол термического разложения твердых топлив и некоторых нефтей содержит различные концентрации микропримесей многоядерных ароматических углеводородов, обладающих канцерогенными свойствами. Важнейшим и наиболее характерным их представителем является 3,4-бензпирен. Сведения о его реакционной способности и поведении, в частности в условиях хранения и использования указанных технических продуктов, немногочисленны и носят в основном качественный характер.

В настоящем сообщении приводятся результаты первого этапа количественного исследования, поставленного с целью изучения кинетикн превращения 3,4-бензпирена, растворенного в бензоле, в присутствии воздуха под воздействием ультрафиолетового облучения при широком варьировании концентрации реагента. Последнее обстоятельство определило выбор растворителя, поскольку исследуемсе вещество наилучшим образом растворяется в бензоле.

По данным ['], 3,4-бензпирен неактивен по отношению к фотоокислению; позднейшие работы $[2-4]$ показывают, что степень фотохимического превращения его при облучении ультрафнолетовым светом (растворы в метаноле и циклогексане) варьирует в пределах от 20 до $50 \%$ при экспозицин от 20 до 40 ч в зависимости от рода растворителя, мощности источника облучения и длительности обработки. В работе $\left.{ }^{4}\right]$ указано, что продукты фотоокисления в метанольном растворе представляют собой бенз-(а)-дионы с размещением кислорода в положениях 6,12-; 1,6- и 3,6-.

\section{Методика}

Основная часть исследования включает пять серий опытов с варьированием концентрации 3,4-бензпирена в растворе в пределах 3,45; 5,$0 ; 28,5 ; 47,5$ и $255 \cdot 10^{-6}$ г/м при температуре $25 \pm 1^{\circ} \mathrm{C}$ и длительности облучения вплоть до 12 и (в первой серии - до 20 и).

Раствор заданной концентрации в количестве 6,0 мл помещается в терметичную кварцевую кювету с внутренним диаметром 9 и высотой 100 мм, снабженную в верхней части пришлифованной пробкой. Неизменный во всех случаях объем воздуха над жидкостью в облучаемом пространстве составляет 1,5 мл. Облучению подвергается одновременно шесть кювет, установленных на общем штативе в термостатнрованном шкафу. Расстояние между центрами поперечного сечения смежных кювет - 20 мм, общая длина штатива (150 мм) соответствует длине облучагщей ртутно-кварцевой лампы ПРК-4, установленной на фиксированном расстоянии (450 мм) от переднего обреза штатива. Кюветы последовательно удаляются из камеры облучения через каждые 2 и. 
Опыты дублируются до получения сходящихся результатов. В эксперименте использованы бензол марки «цда» и 3,4-бензпирен марки «ч».

Содержание 3,4-бензпирена в пробах определяется последовательным хроматографическим разделением смеси в тонком незакрепленном слое окиси алюминия (в нисходящем потоке) и на ацетилированной бумаге с последующей количественной спектрофотометрией в ультрафиолетовой области при максимуме поглощения в полосе 389 нм (прибор СФ-4А). Точность определения - около $2 \%$.

Дополнительные эксперименты поставлены в трех сериях кинетических опытов. В шестой (первой дополнительной) серии об́ъем воздуха увеличен вдвое - до 3,0 м., а количество облучаемого раствора снижено до 4,5 мл. Концентрация реагента в растворе $-3,40 \cdot 10^{-6}$ мг/л (та же, что в первой серии), длительность экспозиции - 20 ч. Эксперимент предпринят для выяснения роли кислорода в процессе превращения 3,4-бензпирена.

Седьмая серия посвящена облучению «холостых» проб растворителя для оценки его поведения в данных условиях. По аналогии с радиолизом бензола в присутствии окисляющих агентов $\left[{ }^{5,6}\right]$ при ультрафиолетовом облучении, как показывает исследование, образуется незначительное количество «первичных» продуктов его окисления и уплотненных вторичных продуктов взаимодействия активированных молекул (дифенил и «полимеры»). Об этом качественно свидетельствуют спектры для обработанной смеси, снятые в ультрафиолетовой области. При хроматографическом разделении они остаются на «стартовой» линии, так же как и продукты фотохимического превращения 3,4-бензпирена (это также подтверждается результатами спектрального исследования). В связи с весьма низкой концентрацией исходного вещества идентификация и прямое количественное определение выхода продуктов облучения исходной смеси не представилось возможным и явится целью последующих специальных исследований. Во всяком случае подавляющая масса продуктов фотолиза 3,4-бензпирена обладает более высоким молекулярным весом, чем исходное вещество.

Восьмая серия опытов включает облучение «стандартного» дозиметрического ферросульфатного раствора Фрике $[7,8]$; она предпринята с целью определения количества энергии, поглощаемой системой во времени, то есть величины поглощенной дозы. Последнее производится по выходу ионов железа, окисленного до трехвалентного состояния. Этот показатель приравнивается к теоретическому для $\gamma$-радиолиза той же системы при насыщении воздухом (15,5 иона на каждые 100 эв поглощенной энергии). Полученные экспериментальные точки удовлетворительно укладываются на прямой в графике для изменения величины дозы во времени, которая описывается уравнением

$$
D=(1,33 \tau+1,4) \cdot 10^{17} \text { эв/ } л \Omega .
$$

На этом основании удается определить мощность дозы $-1,14 \cdot 10^{14}$ эв/мл.сек, рассчитать величину «радиационного выхода» разложенного 3,4-бензпирена в каждой серии опытов и установить адекватность облучения всех проб в системе независимо от расположения соответствующей кюветы в наборе в ходе эксперимента.

Результаты шести серий кинетических опытов подвергнуты графической обработке; во всех случаях экспериментальные точки из каждой серии удовлетворительно укладываются на прямой, описываемой уравнением типа

$$
C=(b-a \tau) \cdot 10^{-6} 2 / \mu \Omega,
$$


где $C$ - концентрация 3,4-бензпирена в смеси; $\tau$ - время в часах; значения коэффишиентов $a$ и $b$ для каждой серии приведены в таблице.

Результаты обработки приводят к заключению, что данные для серии 1 за период более длительного облучения (от 12 до 20 и) в связи с уменьшением концентрации реагента в смеси к двенадцатому часу почти на один порядок, следует выделить в самостоятельную серию (1а), проведенную при начальной концентрации 3,4-бензпирена $C_{\mathrm{H}} \cong$ $\cong 0,95 \cdot 10^{-6}$ г/M .

\section{Обсуждение результатов}

Рассмотрение результатов графической обработки приводит к заключению, что суммарный процесс фотохимического превращения 3,4-бензпирена в изученных условиях протекает в кинетической области и может быть описан макрокинетическим уравнением нулевого порядка. Определенные на этом основании значения постоянной скорости реакции для основных и дополнительной (шестой) серий опытов в сопоставлении с данными по радиационному выходу трансформированного исходного вещества (или суммарных продуктов его фотолиза) и степени его превращения за 8 и облучения представлены в таблице.

Макрокинетическая характеристика процесса фотолиза 3,4-бензпирена

\begin{tabular}{|c|c|c|c|c|c|c|c|}
\hline & \multicolumn{7}{|c|}{ Серия опыта } \\
\hline niti & 1a & 1 & 2 & 3 & 4 & 5 & 6 \\
\hline \multirow{7}{*}{ 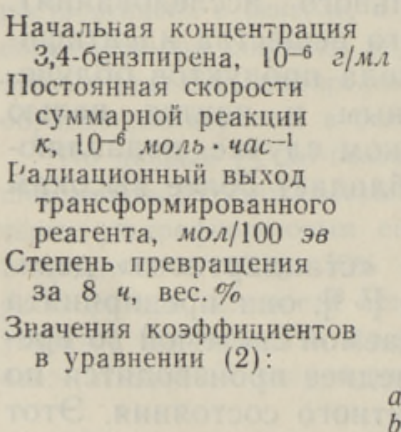 } & 0,96 & 3,45 & 5,0 & 28,5 & 47,5 & 255,0 & 3,40 \\
\hline & 0,30 & 0,89 & 1,0 & 3,97 & 7,94 & 69,5 & 1,29 \\
\hline & & & & & & & \\
\hline & 0,12 & 0,36 & 0,40 & 1,60 & 3,19 & 22,9 & 0,52 \\
\hline & 63,1 & 52,0 & 40,0 & 28,6 & 34,0 & 54,8 & 76,5 \\
\hline & & & & & & & \\
\hline & $\begin{array}{l}0,0072 \\
0,95\end{array}$ & $\begin{array}{l}0,227 \\
3,45\end{array}$ & $\begin{array}{l}0,25 \\
5,0\end{array}$ & $\begin{array}{c}1,04 \\
28,5\end{array}$ & $\begin{array}{c}2,05 \\
47,5\end{array}$ & $\begin{array}{c}16,6 \\
255\end{array}$ & $\begin{array}{l}0,32 \\
3,40\end{array}$ \\
\hline
\end{tabular}

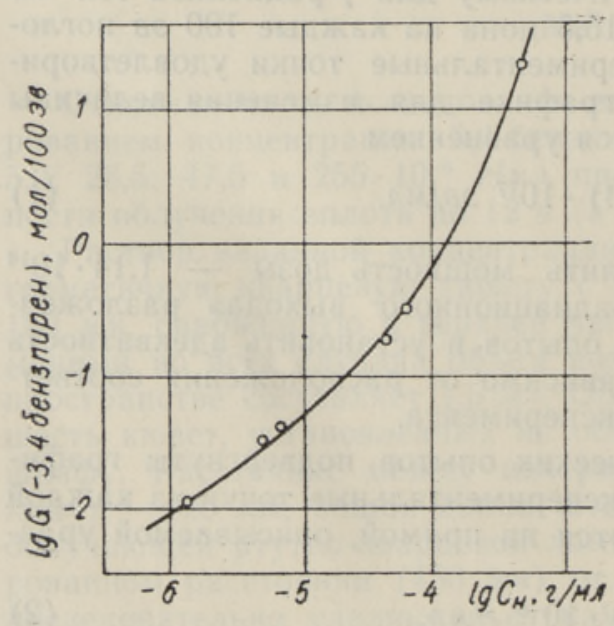

Рассмотрение этих материалов приводит к выводу, что с- повышением начальной концентрации 3,4 бензпирена в растворе величина константы скорости суммарной реакции закономерно возрастает. Эта зависимость имеет экспоненциальный характер и описывается уравнением

$$
k=0,775 C_{\mathrm{H}^{1,35}} \text { моль } 4 a c^{-1} .
$$

Взаимосвязь между радиационным выходом продуктов превраще-

Радиационный выход $(G)$ продуктов фотохимического превращення 3,4-бензпирена как функция начальной концентрации последнего $\left(C_{H}\right)$. 
ния исходного вещества и величиной начальной концентрации последнего более сложна. Она показана на графике.

Примечателен тот факт, что показатели, характеризующие шестую серию опытов, заметно отличаются от данных для первой серии, проведенной при той же начальной концентрации 3,4-бензпирена: скорость реакции и радиационный выход продуктов фотолиза возрастают примерно в полтора раза. Это значит, что суммарный процесс в данном частном случае интенсифицируется с увеличением относительной доли воздуха и, следовательно, кислорода в облучаемой системе (хотя, по ориентировочным подсчетам, при данной $C_{\mathrm{H}}$ избыток кислорода, растворенного в реагирующей смеси, весьма значителен). Между тем попытка установить наличие гидроперекисей в обработанном растворе не увенчалась успехом.

Далее обращает на себя внимание необычно высокий радиационный выход продуктов фотолиза при достаточно большой концентрации 3,4-бензпирена в растворе (например, 3,19 в серии 4 и 22,9 в серии 5), что можно объяснить лишь цепным механизмом суммарной реакции. По-видимому, чересчур низкая концентрация реагента (серии $1-3$ ) обусловливает обрыв зарождающихся цепей. Высказанное соображение находит подтверждение и в характере изменения степени превращения 3,4-бензпирена с повышением его концентрации в изученных пределах: закономерное снижение этого показателя сменяется далее заметным его увеличением по мере создания условий для развития цепных реакций.

\section{Заключение}

Результаты проведенного исследования позволяют с достаточной полнотой охарактеризовать макрокинетику превращения 3,4-бензпирена под воздействием ультрафиолетового излучения в аэрированном бензольном растворе, но недостаточны для углубленного суждения о химизме основных реакций, из которых слагается суммарный процесс. Цепной механизм характерен как для реакций окисления, так и полимеризации, протекание которых возможно при фотолизе 3,4-бензпирена. Попытка такого суждения будет предпринята на основании самостоятельного второго этапа исследования, включающего накопление и изучение состава продуктов фотолиза.

\section{ЛИТ Е РА Т У РА}

1. Пюльм ан Б., Электронная бнохимия, М., 1966.

2. Kuratsune Ma s a n ori, Hirohata T o m i o, Nat. Cancer. Inst. Monogr., No. 9, 1962 (щит. по РЖХим., 8Б802, 1965).

3. B a rneff J., Knerr R. R., Arch. Hyg. u. Bakteriol., Nr. 143 (1959).

4. Antonello C., Carlassare F., Atti Ist. veneto Sci lettere ed arte, Cl. Sci mat. e natur, Nr. 122, 1963-1964.

5. Пше жецки й С. Я., Механизм радиационно-химических реакций, М., 1963.

6. С воллоу А. Радиационная химия органических соединений, М., 1963.

7. Аллен А. О., Радиационная химия воды и водных растворов, М., 1963.

8. Гу бе ргриц М. Я., Бродская Б. Х., Па а льме Л. П., Изв. АН ЭССР, Сер. физ.-матем. и техн. наук, 15, № 3, 462 (1966). 
L. PAALME, M. GUBERGRITS

\section{3,4-BENSPUREENI FOTOKEEMILISE MUUNDUMISE KINEETIKA AEREERITUD BENSEENI LAHUSES}

Katsed näitasid, et aereeritud benseenis lahustatud 3,4-benspüreeni muundumine ultraviolettkiirguse mõjul toimub nulljärgu reaktsiooni järgi. Reaktsiooni kiiruskonstandid ja muundunud 3,4-benspüreeni radiatsioonisaagised erinevate lähtekontsentratsioonide juures on esitatud tabelis. Eriti körged radiatsioonisaagised suuremate lähtekontsentratsioonide puhul on tõenäoliselt saadud lahuses toimunud ahelreaktsioonide tulemusel.

\section{PAALME, M. GUBERGRITS}

\section{KINETICS OF 3,4-BENZOPYRENE PHOTOCHEMICAL DEGRADATION IN AERATED BENZENE SOLUTION}

The paper deals with the results of an experimental investigation concerning the kinetics of 3,4-benzopyrene degradation in aerated benzene solutions under ultraviolet irradiation. The total process is stated to be of the zero-order, data on reaction rate constants and radiation yields of degradated 3,4-benzopyrene (diagr.) as a function of its initial concentration are given in the table. The extraordinary high values of irradiation yields under larger concentrations are evidently due to the development of chain-reactions. 